\title{
Amuletos-placa de iconografía egipcia: El modelo Vaca/Udjat en el ámbito Fenicio-Púnico
}

\author{
María J. LÓPEZ GRANDE y F. VELÁZQUEZ BRIEVA \\ Universidad Autónoma de Madrid, departamento de Prehistoria y Arqueología, y Grupo de Investigación "Ibiza \\ Púnica" ${ }^{1}$.
}

\section{Resumen}

El objetivo fundamental de este trabajo es comprobar si los amuletos-placa hallados en el ámbito mediterráneo, que presentan la doble iconografía vaca/udjat son piezas de creación egipcia, o si trata de derivaciones mediterráneas realizadas a partir de prototipos egipcios. La casi total inexistencia de este modelo concreto en Egipto permite sugerir su posible creación en talleres fenicio-púnicos y su dispersión desde los mismos por la cuenca del Mediterráneo.

Palabras Clave: amuletos, Egipto, fenicio-púnico, vaca, udjat, esteatita.

\section{Summary}

The aim of this study is to confirm either the Egyptian origin of the double-sided plaque amulets with cow/udjat iconography found in Mediterranean ancient sites, or to ascribe them to Phoenician-Punic craftsmen. The scarce evidence of these specific amulets in Egypt, allow us to suggest that they were the result of Phoenician-Punic workshops, where these pieces were made following Egyptian prototypes and then spread across the Mediterranean area.

Keywords: amulets, Egypt, Phoenician-Punic, cow, wdjat, steatite.

Las páginas que siguen, en las que abordamos el estudio de un tipo concreto de amuleto de iconografía egipcia, sus variantes, materias primas y dispersión en el ámbito fenico-púnico, están dedicadas al profesor Manuel Bendala Galán en reconocimiento a su magisterio y a la sabia y generosa dedicación que siempre ha dispensado a sus alumnos, a la vida universitaria y a la investigación.

\section{INTRODUCCIÓN}

Entre el amplio conjunto de amuletos de iconografía egipcia documentado en contextos arqueológicos correspondientes al primer milenio a. C. en los ámbitos próximo oriental y mediterráneo, existe un modelo consistente en pequeñas placas cuadrangulares o circulares, que presentan decoración en una o ambas caras. Están realizadas fundamentalmente en esteatita, pero también son abundantes los ejemplares en fayenza, siendo su sistema de sustentación perforaciones transversales realizadas en el amuleto.

El repertorio figurativo de estos objetos suele ser reiterativo. Las imágenes más frecuentes son una vaca al paso, a veces acompañada de su ternero, en una escena descrita como un paisaje niló-

1 Este trabajo se adscribe a la línea de estudio seguida por el del que las autoras son integrantes. 
tico, evocado mediante la inclusión de flores de papiro a la espalda de la vaca, y el udjat u ojo sagrado. Ambos temas, la vaca en los marjales del Nilo y el ojo sagrado, son propios de la iconografía egipcia, donde cuentan con una larga tradición y están atestiguados, por separado o de forma conjunta, sobre soportes muy diversos; sin embargo, su expresión simultánea, contrapuesta en las caras de los amuletos-placa hallados en Egipto, está documentada en muy pocos ejemplares siendo mucho más frecuente el uso de otros motivos iconográficos, o bien la representación de la vaca disociada del ojo sagrado, o más usualmente la del ojo en solitario.

En este estudio nos hemos centrado en el análisis de los ejemplares del ámbito mediterráneo que presentan la doble iconografía vaca/udjat, dado que la coexistencia de ambos motivos se constata en el mayor número de amuletos-placa conocido en el ámbito fenicio-púnico y su zona de influencia. La casi total inexistencia de este modelo concreto en Egipto nos hace pensar en su posible creación en talleres fenicio-púnicos o, cuando menos, la acogida en dichos enclaves de un tipo originariamente egipcio con escaso éxito en su lugar de origen que contó, sin embargo, con una alta aceptación en el ámbito mediterráneo, donde habría sido reproducido por artesanos fenicio-púnicos.

Nuestro objetivo fundamental es comprobar, a partir de la documentación disponible, si los amuletos-placa con la doble decoración vaca/udjat son genuinamente egipcios o si se trata de derivaciones mediterráneas realizadas a partir de prototipos egipcios. Para presentar esta investigación y nuestras conclusiones, incluimos un breve análisis de los orígenes de los amuletos-placa en Egipto, así como de los motivos iconográficos: la vaca y el udjat u ojo sagrado, para describir y valorar a continuación los ejemplares hallados fuera de Egipto que presentan la iconografía estudiada.

2 Londres, University College, UC 71663.

3 Hölbl, 1989, Lám. 9,7 a-b, procedente de Malta; Velázquez, 2007: Lám. 42,1, procedente de Ibiza.

4 Las piezas del Metropolitan Museum de Nueva York, MMA 26.8.109, MMA 26.8.10 y MMA 26.8.111, consideradas durante décadas como ejemplares de la dinastía XVIII

\section{EGIPTO: ORÍGENES DEL MODELO, MORFOLOGÍA Y TEMAS DECORA- TIVOS}

En Egipto se conocen amuletos-placa cuadrangulares de iconografía diversa al menos desde comienzos de la dinastía XVIII (c. 1550-1295 a. C.). Los motivos representados pueden ocupar una o ambas caras y los ejemplares de doble faz ofrecen una rica variedad de combinaciones. Se conocen así mismo modelos de perímetro redondeado en cuya decoración es predominante el ojo divino, representado en una o en ambas caras, existiendo en este formato circular algunos ejemplares $^{2}$ que muestran en el recto el ojo sagrado y en el verso el rostro del dios Bes, prácticamente coincidentes a los localizados en el ámbito fenicio-púnico ${ }^{3}$.

Los ejemplos más tempranos de forma cuadrada están mayoritariamente realizados en fayenza pero también en esteatita y pasta de vidrio (Pinch, 1993: $165-168)^{4}$. El motivo iconográfico predominante, que perdurará con éxito hasta época ramésida (dinastías XIX-XX, c. 1295-1069 a.C.), es el tema de la vaca al paso, a veces sobre plantas de loto o papiro, en barca vegetal o recibiendo ofrendas. El animal suele portar el disco solar entre las astas, a veces coronado por plumas de avestruz, y un collar menejet al cuello; la escena puede completarse con otros elementos vegetales y/o signos jeroglíficos 5 .

La protagonista indiscutible de este tema iconográfico es Hathor, la vaca divina con connotaciones de diosa madre y nutricia, así como una manifestación de la misma divinidad conocida como Mehet-weret (Kákosy, 1982: 3-4), diosa vaca de carácter cósmico, asociada a las aguas que fluyen y al renacimiento de los difuntos, que habitaba en un bosque de papiros. En el Capítulo 17 del Libro de los Muertos Mehet-weret es equiparada al ojo sagrado de Re, símbolo de carácter mágico y protector manifestado en la forma del udjat, que surgió, según el mismo texto, de entre los muslos de la vaca sagrada (Faulkner, 1985: 44-50). En el Capítulo 186 del mismo corpus

(Winlock, 1948: Lám. XIII), han sido reconocidas recientemente como falsificaciones modernas (Lilyquist, 2003: 282, Fig. 238, d; López Grande et alii, e.p.).

5 Londres, Museo Británico (en los sucesivo MB), EA 43156, incluye el signo jeroglífico nefer frente a la cabeza del animal. 
Hathor, con idéntica iconografía a la de Mehetweret, es asociada al ojo de Re que aparece representado sobre el rostro de la vaca en la viñeta correspondiente (Faulkner, 1985: 185-187).

La iconografía del udjat sobre los amuletosplaca egipcios se constata con regularidad a partir del período ramésida. Su expresión más básica consiste en un ojo sobre el que se indica la ceja y al que se añaden en su parte inferior unas marcas características que imitan las propias de los halcones en su zona ocular: un lagrimal indicado en la zona anterior y una espiral o voluta en la posterior. El ojo, así modificado, se equipara en ocasiones al del dios halcón Horus y es denominado en egipcio udjat. El término proviene de la raíz "ser próspero", "estar sano" (Erman y Grapow, 1982: 399, 8) y puede traducirse "el sano" aludiendo al ojo dañado de Horus que fue sanado por Thot, o evocar el ojo del dios halcón que no fue herido ${ }^{6}$.

El udjat fue así mismo identificado con el ojo de Re, según aparece mencionado en los Textos de los Ataúdes (Carrier, 2004: 815, 335)7, el Papiro Mágico Harris I, 9 y el Libro de los Muertos en donde además se equipara con la diosa Mehet-weret. En estos casos se alude al ojo derecho del dios, que aparece en la mitología egipcia especialmente encargado de proteger de sus enemigos al propio dios Re, y por extensión a aquellos bajo la protección del ojo divino.

A partir de los ejemplos señalados, parece evidente que en las fuentes egipcias los dos temas iconográficos tratados, la vaca en los marjales del Nilo y el ojo del dios, están fuertemente relacionados y equiparados en su simbolismo y carácter protector. Quizá sea esta la razón por la que en el pequeño espacio que ofrece la superficie de los amuletos-placa estos motivos se utilizaran en Egipto de forma sustitutiva, pues la inclusión de

6 El amuleto podría simbolizar cualquiera de los ojos de Horus, el recuperado por Thot, identificado con la luna, o el que no sufrió daño alguno, equiparado con el sol. En el relato de este mito se hace referencia a los ciclos lunares (Plutarco, De Iside et Osiride, 373, b, c-e).

7 En este mismo Capítulo 335 también es Thot el que efectúa la curación del ojo de Re.

8 Placas rectangulares y cuadrangulares realizadas en metal, algo mayores en tamaño que los amuletos-placa, sirvieron de soporte a la imagen del udjat y fueron utilizadas desde momentos tempranos del TPI para cubrir la incisión practi- cualquiera de ellos evocaba el sentido de protección emanado de ambos.

El apogeo de los amuletos-placa se desarrollará en Egipto a partir de los primeros reinados del TPI ${ }^{8}$. Durante las dinastías XXV-XXVI (c. 746525 a. C.), serán frecuentes en Egipto los amuletos-placa que presentan el udjat como motivo fundamental; éste puede aparecer inciso en una de sus caras quedando la contraria sin decoración; algunos ejemplos de este modelo proceden de Illahum (Petrie 1891: Lám. LXVIII, 620 y 746) y Heracleópolis Magna (Pérez Die, 2010: 548, núm. 116, Fig. 793). Se conoce asimismo un molde para la creación de placas de estas características, algo más tardías, procedente de Naucratis (Petrie, 1886: Lám. 38, núm. 17).

A partir del Período Saíta el motivo de la vaca, que para esas fechas asumimos se identifica con Hathor e Isis (Yoyotte, 1987: 172-173, 246-247), vuelve a cobrar relevancia en la decoración de los amuletos-placa en Egipto. Suele aparecer con el disco solar entre los cuernos ${ }^{9}$, representada en una o ambas caras mediante incisiones o relieve muy pronunciado sobre amuletos rectangulares o en forma de naos (Reisner, 1907: Lám. XIX; Hornung y Staehelin, 1976: 261-262, núm. 352, Lám. XXXVI; Petrie, 1914: 43-44, tipos 207 y 209, Láms. XXXVII, 207, d, e, f y 209, a-e). Este modelo iconográfico egipcio no suele incluir la figura del ternero, iconografía que por el contrario tendrá gran implantación en el ámbito feniciopúnico atestiguada sobre amuletos-placa, y también en otras producciones propias de esa cultura como marfiles (Barnett, 1974: 11 ss; Uberti, 1988: 415, Fig. 2) o copas metálicas (Markoe, 1985, passim), objetos en los que el tema ha sido tratado con soluciones iconográficas diversas (Matthiae, 1962: 1-31).

cada en los cadáveres en el proceso de momificación (El Cairo, Museo Egipcio, JE 85281, Yoyotte, 1987: 218, núm. 68; MB EA: 8409, 84010 y 58942).

9 En el Museo Arqueológico Nacional (Madrid), se guarda una placa de procedencia egipcia (MAN 10834), en la que aparece representada una vaca llevando el disco solar entre los cuernos y un objeto de adorno en el cuello, destacando la presencia de cuatro tallos de papiro sobre el lomo del animal (Plas, van der y Pérez Die (eds.), 2006: núm. 2); se trata de una iconografía muy similar a la localizada en algunas placas procedentes del ámbito fenicio-púnico. 
No obstante, basándonos en los datos publicados, constatamos en Egipto una acusada escasez de ejemplares que muestren la conjunción iconográfica, que sin embargo será mayoritaria en los amuletos-placa hallados en los contextos fenicio-púnicos de los ámbitos próximo-oriental y mediterráneo, el modelo de la vaca, que puede aparecer con o sin ternero, contrapuesto al udjat. Un ejemplar contextualizado, fue documentado por Petrie en Egipto, en Deffenneh (1888: Lám. XLI, 48) repitiéndose esta tipología en algunos ejemplares dispersos de los que se desconoce su procedencia exacta, localizados en museos y colecciones privadas ${ }^{10}$. Aunque es notable la falta de investigación en los yacimientos egipcios contemporáneos a los contextos de los hallazgos foráneos $\mathrm{y}$, por lo tanto no es posible formular conclusiones definitivas, sí queremos llamar la atención sobre la marcada escasez de la combinación de los motivos iconográficos vaca/udjat en las superficies contrapuestas de los amuletosplaca egipcios ${ }^{11}$.

\section{AMULETOS-PLACA CON LA ICONOGRAFIA VACA/UDJAT EN EL ÁMBITO FENICIO-PÚNICO}

Amuletos-placa de iconografía egipcia aparecen en contextos arqueológicos fenicio-púnicos de los ámbitos levantino y mediterráneo, e incluso en su zona de influencia (García Gandía, 2009: 141-142).

En el ámbito fenicio, en el Levante Mediterráneo, se conocen algunos ejemplares de cronología bastante alta que podrían entenderse como precedentes de la combinación de los motivos vaca/udjat sobre este tipo de soporte.

Amuletos-placas cuadrangulares que presentan en ambas caras el ojo udjat como único motivo, proceden de los yacimientos de Tell Gemme y

10 Estos ejemplares son considerados de procedencia egipcia en la bibliografía consultada. Véase: Hölbl, 1986, Lám. 84, 9 a-b (teóricamente procedente de Luxor); Album Drioton MS 5386, Lám. 489 (Colección Fouad, JE 84137) y Acquaro, 1977: núm. 446, Lám. 17, procedente de la Colección Timón, Museo de Cagliari, núm. 15293. Este último amuleto nos plantea dudas acerca de su atribución egipcia dadas sus características iconográficas propias de ejemplares tardíos que como explicamos a continuación, consideramos probablemente de origen centro-mediterráneo.
Asquelón, ambos en Israel (Herrmann, 1994: 710712, núms. 1106 y 1110) y de la necrópolis de Akzib (Israel), tumba ZR XXIX (Herrmann, 2006: 216, núm. 407, Lám. XCIV), datada entre los siglos IX y VIII a. C. (Dayagi-Mendels, 2002: 81 , núm. 73, Fig. 4.21). Otros hallazgos similares carecen de contexto (Herrmann, 2006: 216, núm. 408, Lám. XCIV).

También un ejemplar de esteatita procedente de la Tumba ZX de la necrópolis de Akzib (Buqbaq) $)^{12}$, presenta sobre una de sus caras un udjat cuya voluta queda definida con una pluma o ala de ave, mientras que el lagrimal se asemeja a una pata de halcón, características iconográficas que se conocen en representaciones muy elaboradas sobre amuletos egipcios ${ }^{13}$. En la superficie contraria del ejemplar de Akzib, se muestra la imagen de un bóvido alado, tumbado a la derecha y tocado con la corona roja del Bajo Egipto (Dayagi-Mendel, 2002: 21, núm. 37, Fig. 3.9; Herrmann, 2006: 222, núm. 428, Lám. XCVII). El contexto asignado a este amuleto corresponde a la fase III del enterramiento, datada entre finales del siglo IX y el siglo VII a. C.

Otro amuleto de características similares procede de Tiro ${ }^{14}$; en una de sus caras aparece el udjat y en la contraria el signo jeroglífico anj entre dos plumas de Maat (Ward, 1991: 93-94, Fig. 12); el hallazgo se ha datado entre los siglos X y VIII a. C.

Otro ejemplar, en este caso de fayenza, localizado en Akko (Israel) ${ }^{15}$, presenta en el recto una escena realizada sin perforaciones, en la que aparece una vaca al paso con el disco solar entre los cuernos; sobre el lomo del animal surgen cuatro tallos de papiro coronados por flores indicando un paisaje nilótico, completado con otro motivo vegetal situado bajo la cabeza del bóvido. En el verso se desarrolla una inscripción jeroglífica referida a Horus del doble horizonte y a la diosa Sejmet (Herrmann, 2002: 105-106, núm. 86). Al

11 W.A. Ward (1991: 94) opina que la conjunción de estos motivos no existe en esta clase de amuletos en Egipto.

12 Jerusalén, Museo de Israel, núm. 48-74.

13 MB EA 29222 (Andrews, 1994: Fig. 46 a).

14 Esta placa, realizada en esteatita, fue localizada junto a once escarabeos en el interior de un conjunto de urnas conteniendo cremaciones, al lado de las cuales aparecieron varias estelas fenicias; los doce ejemplares son considerados por W.A. Ward importaciones egipcias.

15 RegNr. AK VI K1 72 2830/120 (Herrmann, 2002: 105). 
contexto de hallazgo de esta pieza se le asigna una cronología bastante tardía, del siglo VI a. C., aunque el amuleto es datado por Herrmann entre el 900 y el 600 a. C. (Herrmann 2002: 8, 107).

Contextos análogos, de cronología similar, ofrecen en el ámbito fenicio-púnico los primeros testimonios de la combinación de las iconografías vaca sin ternero/udjat, sobre amuletos-placa rectangulares, presentando unas características que corresponderían al primer tipo que diferenciamos en este trabajo. A este grupo corresponde el ejemplar también procedente de Akko (Herrmann, 2006: 221-22, núm. 427, Lám. XCVII ${ }^{16}$, realizado en esteatita ${ }^{17}$ (Fig. 1). En el recto aparece una vaca al paso a la derecha, con el sol indicado mediante una perforación circular practicada en la placa entre los cuernos del bóvido, y tres flores de papiro talladas en el soporte sobre el lomo del animal. La parte inferior de esta cara del amuleto está fracturada, por lo que no es posible determinar la existencia del elemento vegetal bajo la cabeza del bóvido, motivo que parece característico en este modelo iconográfico. La decoración del verso aparece indicada mediante perforaciones e incisiones, mostrando un udjat que posee las mismas peculiaridades que las comentadas para el ejemplar procedente de $\mathrm{Akzib}^{18}$, la voluta en forma de ala y la pata de halcón labrada en el lagrimal. Este amuleto fue hallado en superficie, no pudiéndose determinar su datación contextual. Herrmann data esta pieza, de acuerdo a su iconografía, entre el 900-600 a. C.

Otro amuleto-placa perteneciente a este primer grupo, presenta esta misma iconografía vaca/udjat. Procede de la necrópolis norte de Akzib (Tumba I fase 3, Loc. 02-201) ${ }^{19}$, y está realizado al parecer en hueso, con las imágenes marcadas mediante perforaciones (Herrmann, 2006: 221, núm. 426, Lám. 97; Cowie, 2004: núm. 19)²0. El ejemplar muestra a la espalda de la vaca tres flores de papiro, mientras que el diseño del udjat es sencillo. La cronología derivada del contexto de su hallazgo se ha fijado a finales del siglo IX a. C. (Mazar, 2004: 246). Por su parte, Herrmann sitúa el amuleto entre el 900-600 a. C.

Un amuleto semejante, probablemente de fayenza, hallado en Asquelón (Israel) (Herrmann, 1994: 711-712, núm. 1109) ${ }^{21}$, presenta en una de sus caras una vaca al paso con el disco solar entre las astas, coincidiendo en estos detalles con el ejemplo de Akzib anteriormente comentado, si bien sobre el lomo son sólo dos las flores de papiro mostradas. En la superficie contraria aparece el udjat que carece igualmente de los detalles del ala en la voluta y las patas de halcón en el lagrimal. Lamentablemente, no se conoce el contexto de

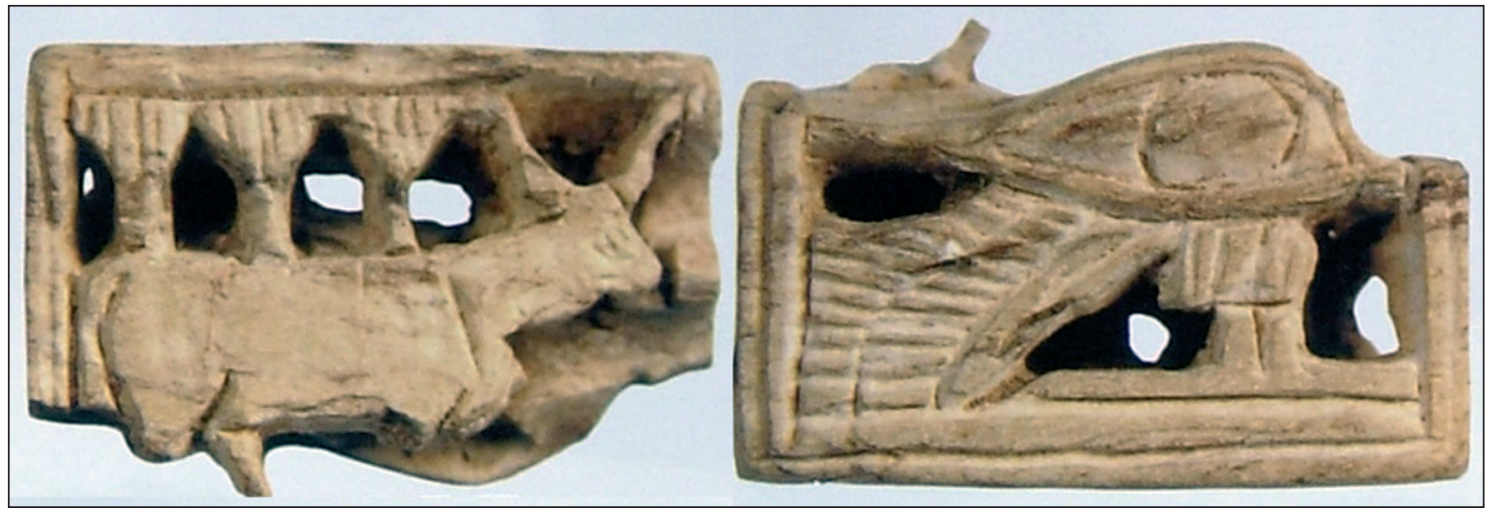

Figura 1. Amuleto-placa procedente de Akko (Israel Antiquities Authority 73218; esteatita, 0,9 x1,3 x 0,45 cm). Representativo del primer grupo (Mediterráneo oriental)

16 Bet-Shemesh, Israel Antiquities Authority, núm. 73218.

17 Herrmann (2006: 221) considera que esta pieza está realizada en hueso, pero el examen visual de fotografías de la misma, sugiere, en nuestra opinión, que está tallada en esteatita.

18 Jerusalén, Museo de Israel, núm. 48-74.

19 Jerusalén, Instituto Arqueológico de la Universidad Hebrea, núm. 2294.
20 Lamentablemente no hemos podido confirmar el material sobre el que está tallado este amuleto, pero un examen visual de fotografías del mismo nos hacen pensar que podría tratarse de esteatita.

21 Asquelón, Shulamit Garden Hotel, Leo Levi Expedition, s/n. 
este ejemplar que Herrmann data entre el 700-600 a. C. (Herrmann, 1994: 710).

No hemos encontrado documentada la presencia de amuletos con esta iconografía en la información que Herrmann $(1994,2002,2006)$ aporta de otros yacimientos de la zona de Palestina/Israel, aunque hemos constatado ejemplares muy similares, sin contexto conocido, pero al parecer procedentes de la zona fenicia, en una colección particular' ${ }^{22}$ (Gubel, coord. 1987: núm. 317), así como formando parte de la Colección De Clercq (Ridder de, 1911: 431, 432, núms. 2383 y 2391).

Es interesante destacar la aparente escasez de amuletos-placas con la iconografía vaca/udjat en los yacimientos de influencia fenicia de la zona próximo-oriental ${ }^{23}$, así como la falta de hallazgos de estas piezas en el resto de los yacimientos levantinos de cultura distinta a la fenicia.

En Chipre se han localizado amuletos-placa que representan el udjat en solitario en la necrópolis de Marion (Ohnefalsch-Richter, 1893: 208, 212, Lám. XXV,7), el sitio II de Kition ${ }^{24}$ (Clerc et alii, 1976: Kit 441 y Kit 708, Láms. XVII y XVIII) y la necrópolis de Amathonte ${ }^{25}$ (Clerc, 1991: 84, 137). También se constata el motivo del ojo sagrado asociado a otras iconografías sobre algunos ejemplares, como el procedente de la necrópolis de Amatonthe ${ }^{26}$ (Clerc, 1991: 80, 137), que ostenta el udjat en el recto y un uraeus junto a un cinocéfalo en el verso.

Centrándonos en los ejemplares chipriotas que alternan en sus caras los motivos vaca sin ternero/udjat, contamos con un testimonio en Kition (sitio II, bothros I, 1,60 m), realizado en fayenza (Clerc et alii, 1976: 144, Kit. 554, Lám. XVIII). La iconografía que exhibe, si bien conocida, muestra algunas peculiaridades que permiten incluirla en un segundo grupo: la escena con la vaca caminando a la derecha, presenta una única flor de papiro sobre el lomo del animal, de mayor tamaño que el de sus homólogas en los amuletosplaca levantinos; el udjat de la cara contraria es de calidad inferior y más esquemático en su diseño,

22 París, Colección M.d.S.

23 Es posible que la Colección De Clerq cuente con algún ejemplar procedente de la zona próximo oriental (Ridder de, 1911: núms. 2376-2382). Las descripciones que efectúa de Ridder no son demasiado aclaratorias, aparte de la problemática referida al origen de las piezas perteneciente a este tipo de colecciones. que los constatados tanto en los ejemplares levantinos como en otros chipriotas. El contexto de aparición de esta pieza se ha datado entre el 600450 a. C., es por tanto algo posterior a los amuletos ya reseñados, tratándose de una variante de este tipo iconográfico que, como veremos posteriormente, será habitual en yacimientos feniciopúnicos del Mediterráneo centro-occidental. Otros ejemplares similares hallados en la isla, son los procedentes del bothros de Kamelarga (Larnaca) (Myres y Ohnefalsch-Richter: 1899: 157, CM 4766) y de la necrópolis de Amathonte, tumba 57 (Smith, 1900: 118) y tumba 9 (Gjerstad et alii, 1935: 56, 60 Lám. XIV, 2 y CLIX, 13, núm. 100, idem, 1948: 172-173, Fig. 38), ambos enterramientos datados en el Chipro-arcaico II (S. VII-VI a. C.).

Avanzando hacia el Mediterráneo central, llegamos a Cartago donde también encontramos varios amuletos-placa, procedentes de diversas zonas de su necrópolis, en los que tanto el motivo de la vaca sin ternero como el del udjat aparecen alternados con otras iconografías diferentes. Podemos citar, entre otros, el amuleto-placa que muestra en una de sus caras la vaca sin ternero, con tres esquemáticas flores sobre el lomo, y en la opuesta una figura de fecundidad sentada a la derecha, sosteniendo en sus manos un vaso tipo hes, delante del cual se desarrolla la inscripción jeroglífica "nefer ra" (Vercoutter, 1945: núm. 472).

Junto a estas piezas aparecen amuletos-placa que contraponen los motivos vaca/udjat, dando lugar a cuatro variantes diferenciadas en las que se aprecian ciertos cambios que si bien sutiles, pueden estar indicando diferentes orígenes y cronologías.

1. Una primera variante perteneciente al primer grupo, ya constado en Levante, ofrece una iconografía casi idéntica a la documentada sobre la placa de $\mathrm{Akko}^{27}$ y mostrada en nuestra Fig. 1, que en la escena de la vaca no ofre-

\footnotetext{
24 K 441 y K 708 (Sitio II, bothros I -1,60 m-, exc. 1966).

25 T 297/5.3 (nivel 600-475 a. C.).

26 T 289/13 (tumba utilizada desde el 700 al 325 a. C.).

27 Bet-Shemesh, Israel Antiquities Authority, núm. 73218
} 
ce diferencias significativas presentando los tres tallos de papiro destacando sobre el lomo, mientras que el udjat presenta la voluta en forma de pluma o ala y el lagrimal transformado en una pata de halcón (Vercoutter, 1945: núm. 899). En el ejemplar cartaginés el ojo sagrado incluye además un ureaus erguido bajo el vértice interno del ojo, un rasgo también conocido en modelos egipcios.

Otros ejemplares similares se han recogido en los niveles arcaicos de la necrópolis de Cartago, datados en los siglos VII-VI a. C. (Gauckler, 1915, I: Tumba 16, Lams. CXVIII y CLXXVI; Tumba 27, Láms. CXXII y CLXVII; Tumba 122, Lám. XXXIII; Tumba 146, Lám. CXXXIX y Tumba 311, Lám. XCVI; Redissi, 1991: Lám. 2, núm. 12).

Es importante señalar que sólo hemos localizado un amuleto de estas características en el resto del ámbito fenicio-púnico centromediterráneo. Se trata del ejemplar hallado en el yacimiento de La Fonteta (Alicante) ${ }^{28}$ (Fig. 2), cuyo contexto de aparición corresponde al nivel Fonteta IV-A, datado en 635625 a. C., cronología coincidente con la de los ejemplares cartagineses.
2. Una segunda variante también documentada en Levante (segundo grupo), se identifica en la necrópolis de Cartago. Aparece sobre amuletos-placa realizados en todos los casos en esteatita (Fig. 3). En ellos se representa en uno de los lados la vaca al paso con una única flor de loto sobre el lomo y en ocasiones un motivo floral bajo su cabeza, dando lugar a una escena muy similar en todos los detalles al ejemplar de fayenza procedente de Kitión ya reseñado (sitio II, bothros I, 1,60 m) publicado por Clerc (1976: 144, Kit. 554, Lám. XVIII). El udjat en la cara contraria es de diseño básico, con voluta y lagrimal sencillos.

Las primeras manifestaciones de amuletosplaca hallados en Cartago que incluyen esta variante, se fechan entre finales del siglo VI (Gauckler, 1915, I: tumba 64, Láms. CXXX y CLXXVIII, tumba 309, Lám. CXI y tumba 146, Láms. XXXIX y CXXXIX) y comienzos del V a. C. (Gauckler, 1915, I: Tumba 177, Lám. XLVIII; Tumba 199, Lám. CXLVIII y tumba 228, Lám. LXXII) ${ }^{29}$.

Encontramos esta misma tipología en Sicilia, en un ejemplar procedente de alguna de las necrópolis de $\operatorname{Mozia}^{30}$ (Fresina, 1980: 39, Fig. I, 3 a-b, Lám. V a-b; Verga, 1981: 21, Fig. 8

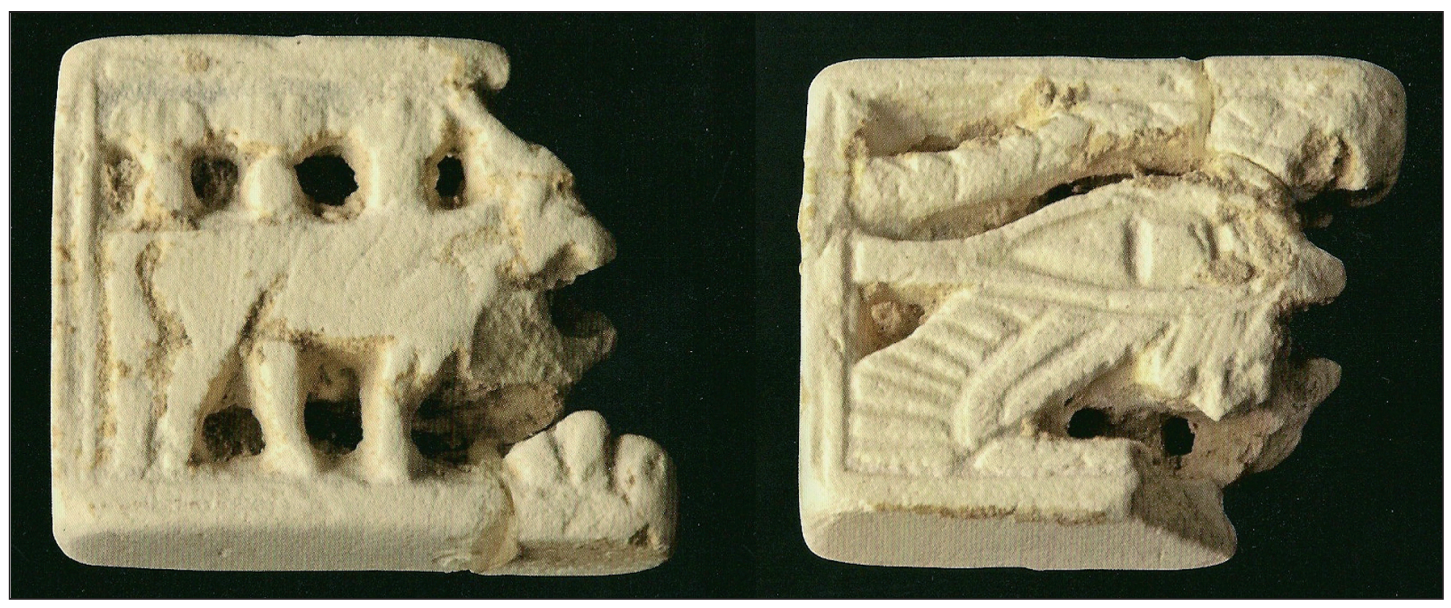

Figura 2. Amuleto-placa procedente de La Fonteta (Museo Arqueológico, Etnológico y Paleontológico Municipal de Guardamar del Segura (Alicante), F-5001; esteatita, 1,14x1,37x0,39).

Representativo del primer grupo (Mediterráneo occidental).

28 Guardamar del Segura (Alicante), Museo Arqueológico, Etnológico y Paleontológico Municipal, F 5001 (Escolano, 2010: 70-71).

29 La continuidad del tipo en el siglo IV a. C. es defendida por T. Redissi (1991: 100) basándose en el hallazgo de la tumba 3 de la necrópolis de Gebel Mlezza (Kerkuán) (Cintas y Gobert, 1939: 149, Fig. 11); sin embargo al encontrarse el amuleto fragmentado no es posible conocer si pertenece a esta variante iconográfica o a la que representa a la vaca amamantando a su ternero.

30 El amuleto se encuentra en el Museo Whitaker (núm. 1608) por lo que su procedencia de Mozia es segura, pero no se conoce en cuál de las necrópolis excavadas fue hallado, si de la localizada en el islote donde se ubica la ciudad o en la de Birgi, situada en la costa enfrente del mismo. 


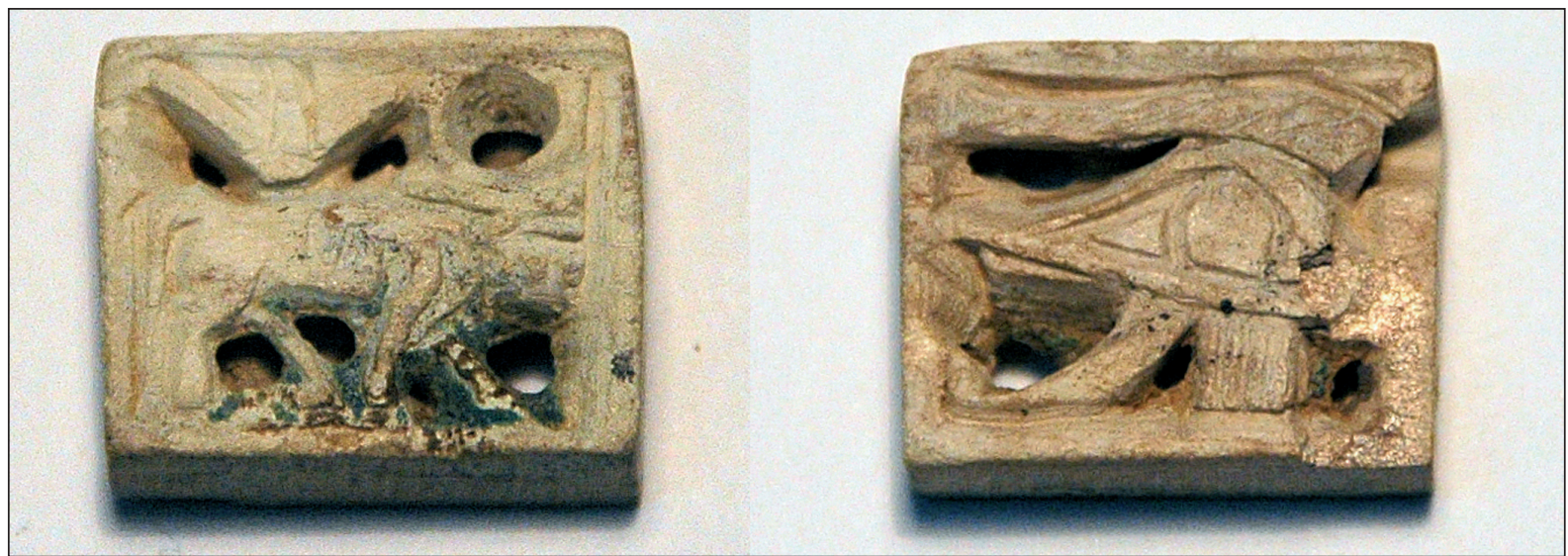

Figura 3. Amuleto-placa procedente de Ibiza (MAN 1923/60/2093; 1,05 x 1,25 x 0,4 cm). Representativo del segundo grupo.

a-b); otro amuleto similar se localizó en la necrópolis de Palermo (Gabrici, 1941: 270, Fig. 14). Lamentablemente no se tienen datos acerca del contexto arqueológico y cronología de estas piezas, si bien en trabajos mas recientes ha sido documentado un ejemplar en la necropolis de Solunto, datado por Termini entre finales del siglo VI-V a.C. (Termini, 1995: 98-100, Tumba 111, núm. 3, Fig. 1, c, Lám. I, 3).

Más abundantes son los hallazgos en Cerdeña, donde se ha localizado un importante número de ejemplares de esta variante iconográfica, algunos carecen de contexto (Acquaro, 1977: núms. 460-464, 466, 467, 470), y de otros se conoce su procedencia de distintas necrópolis de la isla, como Nora (Patroni, 1904: Lám. XVI, 1, tumba XXIX; Acquaro, 1977: núm. 469, Lám. XIX), Cagliari (Predio Ibba, tumbas 8 y 32, Taramelli, 1912: 176, 182 y San Avendrace, tumba 32, Puglisi, 1942: 102, Fig. 6;
Acquaro, 1977: núms. 465, 468, Lám. XIX) y Tharros (Acquaro, 1982: núms. 78-80, Lám. IV; Mendleson, 1987: 111, tumbas 3, 10, 20, 22, 28 (2), 29). La datación de estos ejemplares entraña dificultad al tratarse de tumbas de hipogeo cuyo uso se prolonga en el tiempo, y que en ocasiones fueron objeto de reutilización en época posterior.

En Ibiza también se localizan ejemplares de esta tipología, procedentes de la necrópolis del puig des Molins (Vives, 1917: núm. 640; Lám. XXXVII, 19; Fernández y Padró, 1986: núms. 240, 244, 247, Láms. XVI-XVII; López Grande et alii, e.p.: núms. 664 - 669). Lamentablemente ninguno de ellos cuenta con un contexto susceptible de ser datado.

3. Una tercera variante documentada en la necrópolis de Cartago, que constituye el tercer grupo, se presenta sobre ejemplares que en su mayor parte están elaborados en esteatita (Fig. 4), aunque existen algunos realizados en un tipo de fayenza poco densa con

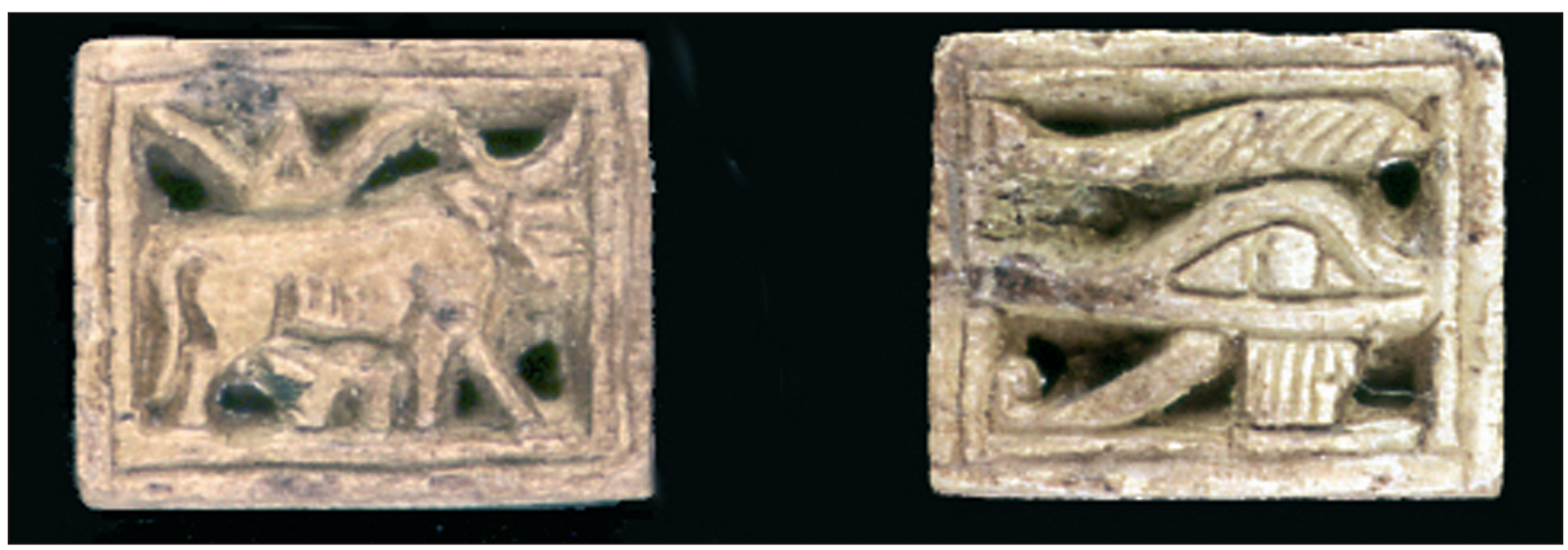

Figura 4. Amuleto-placa procedente de Ibiza (MAEF 6808; esteatita, 1,6 x 2 x 0,55 cm). Representativo del tercer grupo. 
vidriado verdoso. En ellos, la vaca, al paso aparece acompañada de un ternero usualmente bajo sus patas, amamantándose, aunque existe algún ejemplar en el que se sitúa delante de la vaca (Moscati, 1988: 699, núm. 684). La escena se completa con una flor de papiro sobre su $1 \mathrm{omo}^{31}$, detalle coincidente con la segunda variante iconográfica diferenciada, y una especie de elemento vegetal situado bajo la cabeza del bóvido, detalle frecuente en el conjunto de los ejemplares conocidos de este tema iconográfico. El udjat contrapuesto es de diseño sencillo, careciendo de voluta alada y pata de halcón.

Los amuletos-placa que exhiben esta tercera variante, se localizan en los contextos funerarios cartagineses contemporáneos a mediados del siglo VI a. C., tanto en la zona de Byrsa (tumbas 19-08-1899 y 4-10-1899) como de Dermech (Gauckler, 1915 I: tumba 146, Láms. XXXIX y CXXXIX y 158, Lám. CXL), con una prolongación en el siglo $\mathrm{V}$ a. C. (Gauckler, 1915 I: tumba 199, Láms. CXLIV y CXLVII).

Al igual que en la segunda variante, de esta tercera existen ejemplares documentados en diferentes yacimientos fenicio-púnicos del Mediterráneo centro-occidental. En Sicilia, un ejemplar elaborado en esteatita procede de Mozia (Fresina, 1980, Fig. 1,2; Verga, 1981: 20 , Fig. 7 a y b), sin que se conozcan datos sobre su contexto de aparición que permitan sugerir una cronología para el mismo. En trabajos recientes ha sido documentado un nuevo ejemplar contextualizado en una inhumación infantil de la necrópolis púnica de Palermo, datado en el último cuarto del siglo VI comienzos del V a.C. (Di Stefano, 2009: 187-188, tumba 63, núm. 20, Fig. 24, 6-7).

En Cerdeña son abundantes; algunos carecen de contexto dentro de la isla (Acquaro, 1977: núms. 448-452, 454-459), pero se conoce la procedencia de ejemplares localizados en las necrópolis de Tharros (Acquaro, 1982: núms. 74-77, Lám. IV, idem, 2004: 238-239, Lám. XXIX 1-2; Mendleson, 1987: tumbas 9, 11,

31 En algún ejemplar la flor es representada en el sentido perpendicular a la escena (Redissi, 1991: Lám. 2, núm. 10).

32 MAN 1923/60/2092.

33 El único contexto conocido es el del amuleto-placa conservado en el Museo Arqueológico de Ibiza y Formentera
16, 32), Cagliari (San Avendrace, tumba 5/7 XII-1970, Acquaro, 1977: núm. 453, Lám. XVIII), Sulcis (Savio et alii, 2004: núm. 47, Fig. 64-65) y Panilogira (Hölbl, 1986 Lám. 87/3). En algunos ejemplares de esta tercera variante pueden observarse algunos detalles singulares, como la aparición de dos flores de loto sobre el lomo de la vaca en una placa realizada en fayenza (Acquaro, 1977: núm. 449; Hölbl, 1986: Lám. 85/1), o la derivación de estos motivos en una roseta (Vercoutter, 1945, núm. 898; Mendleson, 1987: núm. 32/37, Lám. 136).

El material de estos amuletos sardos es predominantemente la esteatita, pero también, al igual que en Cartago, existen algunos realizados en fayenza. El uso de una materia prima u otra resulta relevante ya que incide de forma marcada en el aspecto final de la pieza, debido a las distintas posibilidades que cada material ofrece. Así, los ejemplares trabajados en esteatita poseen un mayor grado de relieve conseguido mediante perforaciones talladas en la placa, mientras que los realizados en fayenza presentan usualmente menos relieve, careciendo en ocasiones de perforaciones.

En Ibiza ésta es la variante más abundantemente localizada en la necrópolis del puig des Molins (Vives, 1917: núm. 640, Lám. XXXVIII, 17 y 18; Gamer-Wallert, 1978: núm. B 130; Fernández y Padró, 1986: núms. 234-239, 242, 246, 248, Láms. XV y XVI; Plas, van der y Pérez Die (eds.), 2006: núm. 408; López Grande et alii e.p.: núms. 671684). Un único ejemplar procede de otra necrópolis existente en la isla, can Cardona (Fernández y Padró, 1986: núm. 241, Lám. XV-XVII; López Grande et alii e.p.: núm. 670) Su material de elaboración, con una única excepción ${ }^{32}$, es la esteatita, y los detalles iconográficos responden a los característicos de esta variante. No pueden aportarse datos acerca de su cronología ${ }^{33}$.

Por último, en la Península Ibérica se han localizado varios ejemplares que responden a 
la iconografía que muestra la vaca amamantando a su ternero, procedentes tanto de yacimientos fenicio-púnicos ${ }^{34}$ : el santuario de Corham's Cave (Gibraltar) (Padró, 1985: núm 31.34), como de otro ámbito cultural ${ }^{35}$ al que se adscriben el ejemplar de la necrópolis de Les Casetes (García Gandía, 2009: 48, 142, Figs. 23, 4 y 147) o el amuleto localizado en Pinos Puente (Granada) (GamerWallert, 1978: 285, núm. G 45). Todos estos amuletos-placa están tallados en esteatita. La cronología sugerida para el ejemplar procedente de la tumba 5 de la necrópolis de Les Casetes es del siglo VI a. C. (García Gandía, 2009: 178).

4. La cuarta y última variante, que define un cuarto grupo, la constituye un conjunto de amuletos-placa realizados todos en fayenza, que presentan igualmente los motivos iconográficos de la vaca amamantando a su ternero en una de las caras y en la contraria el ojo udjat, ambos representados de forma muy esquemática, con los rasgos en ligero relieve. Otra característica de estos ejemplares, es la desaparición de la flor de papiro sobre el lomo de la vaca.

Dentro de la diversidad que presentan los amuletos de este cuarto grupo, podemos hacer dos apartados que comprenden ejemplares muy característicos:

4.1. Se trata de placas rectangulares, algo más grandes que las pertenecientes a las otras variantes reseñadas. Tanto la vaca amamantando a su ternero como el ojo udjat están realizados muy esquemáticamente, y la flor de papiro es sustituida por un rayado paralelo que rellena el campo existente en la zona superior de esa cara; esta técnica decorativa tiene su correspondencia en la superficie contraria con un rayado similar que define la ceja del ojo (Fig. 5). El número de ejemplares localizados no es abundante.

Esta variante se detecta en Cartago entre los siglos IV-III a. C. en las zonas de Ard elMorali (Redissi, 1987: Lám. 36, núm. 397) y el Odeón (idem, Lám. 36, núm. 398), existiendo ejemplares procedentes de las necrópolis norteafricanas de Gebel Mlezza (Kerkouan), tumba 1, datada en el S. IV a. C. (Cintas y Gobert, 1939: 147, 150: Fig. 10) y El-Mansourah (Kélibia), tumba 5, con cronología ya de finales del S. IV comienzos del III a. C. (AA. VV. 1987: 92-93, núm. 11).

En Sicilia se ha localizado un amuleto-placa de estas características procedente de Mozia (Fresina, 1980, Fig. 1,1; Verga, 1981: 22, Figs. 9 a-b), y otro en Selinunte (Sfameni Gasparro, 1973: Lám. XLVIII, Fig. 79 a-b, p. 198, núm. 107), sin que puedan aportarse datos contextuales ni cronológicos.

Piezas similares se encuentran en Cerdeña sin contexto documentado (Acquaro, 1977: núm. 447, Lám. XVIII), y también procedentes de las necrópolis de Sulcis (Pesce, 1961;

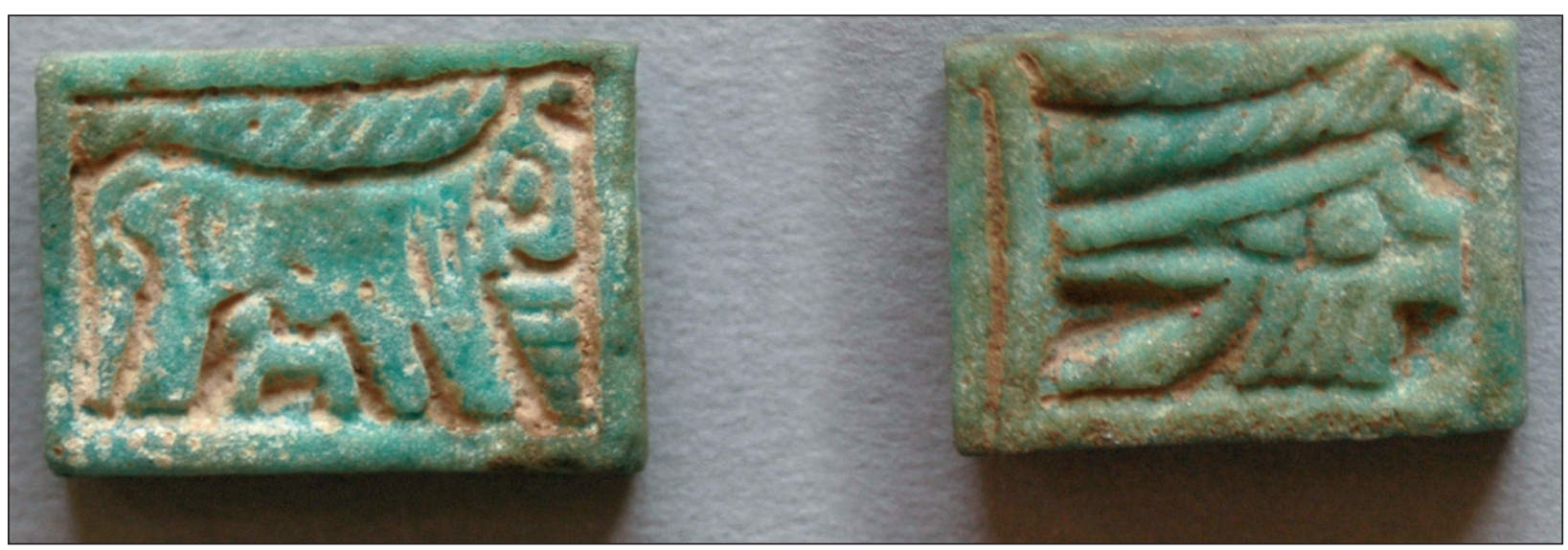

Figura 5. Amuleto-placa procedente de Ibiza (Museo del Cau Ferrat (Sitges, Barcelona), 30365-8; fayenza, 1,5 x 2,1 x 0,5 cm). Representativo del cuarto grupo, primera variante.

34 Es probable que pertenezca a esta variante el ejemplar procedente de la tumba 5 B de Puente de Noy (Granada), cuya datación se estima en la primera mitad del siglo $\mathrm{V}$ a. C.
(Molina et alii 1982: 196, Fig. 112).

35 Otra de estas placas podría proceder de Ampurias (Padró, 1983: 61-62, núm. 07.22). 
Fig. 135), Tharros (Mendleson, 1987: 9/33, Lám. 91) y probablemente Nora (Hölbl, 1986: Lám. 85, 2 a-b).

En Ibiza se ha localizado un número relativamente importante de ejemplares de esta variante, procedentes de la necrópolis del puig des Molins (Vives, 1917: núm. 640, Lám. XXXVIII,16; Gamer-Wallert, 1978: núms. B 131 y B 132, Lám. 47; Fernández y Padró, 1986: núms. 249-250, Lám. XVII; López Grande et alii, e.p.: núms. 690-698). Lamentablemente no contamos con datos contextuales que permitan establecer su datación.

4.2. El segundo grupo de amuletos-placa integrantes de la cuarta variante, presenta como rasgo característico su pequeño tamaño y su forma cuadrada; están elaborados en fayenza vidriada con un barniz verde muy brillante que no es característico del resto de amuletos de tipo egipcio. Iconográficamente presenta también grandes diferencias con el conjunto de placas vaca/udjat analizado, puesto que tanto la representación de la vaca con su ternero como la del udjat están tratadas de forma muy diferenciada, no sólo por su esquematismo, sino también por los rasgos iconográficos de sus protagonistas: la figura de la vaca está representada prácticamente por un cuadrúpedo cuya identificación podría dudarse, de no ser conocida su atribución por el resto de la serie. Sobre el animal, la flor de papiro ha desaparecido para dar paso a los signos astrales del sol y la luna (Fig. 6).

Piezas características de esta variante se han documentado sólo en Cerdeña, con ejemplares procedentes de Sulcis (Hölbl, 1986: Lám. 86, 4 a-b y 5 a-b), y en Ibiza (Vives, 1917: 98 ,
Lám. XXXIII, 7; López Grande et alii, e.p.: núms. 700-701).

Tampoco estos amuletos cuentan con datos acerca de su contexto y cronología.

\section{CONCLUSIONES}

Constatada en la arqueología egipcia la marcada escasez, prácticamente ausencia, de la combinación de los motivos iconográficos vaca/udjat en las superficies contrapuestas de los amuletosplaca egipcios, y dada la relativa abundancia del tipo en hallazgos realizados fuera de Egipto, nos planteamos si los objetos que responden a este formato e iconografía, ambos de tipo egipcio, tuvieron su origen en Egipto o fueron piezas producidas por talleres fenicio-púnicos.

Ante este problema podemos sugerir dos explicaciones alternativas. Una primera opción sería que, como los motivos iconográficos proceden claramente de Egipto y su incorporación sobre placas también se constata sobre amuletos egipcios, aunque habitualmente disociada, sería en el ámbito fenicio donde a partir de modelos egipcios representando únicamente la vaca pasante o el ojo udjat, se habría llegado a esta combinación tan característica detectada en los amuletos analizados en este estudio. Se justificaría así el insignificante número de ejemplares localizados en Egipto. Probablemente esta creación habría tenido lugar en el ámbito fenicio levantino para posteriormente extenderse a lo largo del Mediterráneo donde pudo haber sido copiado y modificado.

Una segunda explicación se ajustaría a la siguiente concatenación de hechos: 1) producción de estos objetos en talleres egipcios, 2) escaso

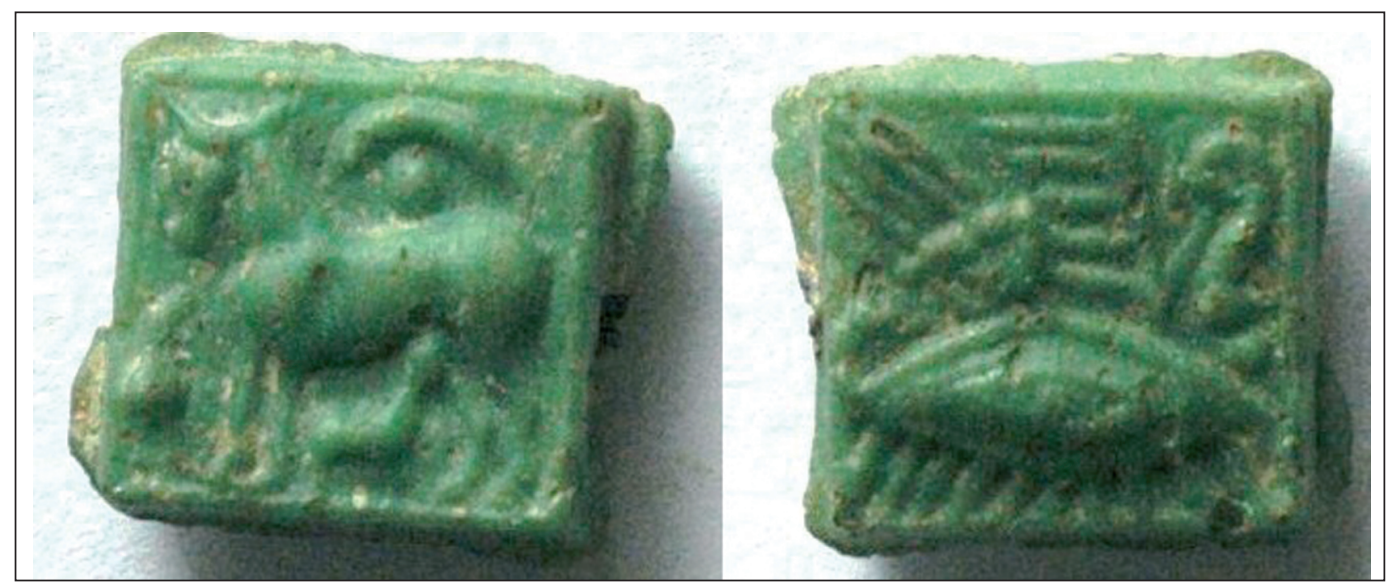

Figura 6. Amuleto-placa procedente de Ibiza (Colección Bauçà (Felanitx, Mallorca), 2, fayenza, 1,8 x 1,1 x 0,3cm). Representativo del cuarto grupo, segunda variante. 
triunfo del modelo frente a otros contemporáneos, 3) aceptación del mismo fuera de Egipto, 4) consecuente utilización en la época y presencia en el registro arqueológico. Esta posibilidad podría apoyarse en la existencia de algunos ejemplares procedentes del ámbito fenicio-púnico, cuyas características iconográficas junto a las inscripciones jeroglíficas que en algún caso incluyen, les hacen, casi con seguridad, candidatos a ser piezas de producción egipcia a pesar de no haberse localizado ejemplares idénticos en Egipto de forma significativa. Este hecho podría avalar la existencia de una fabricación egipcia de amuletos-placa con iconografías muy diversificadas, cuya asociación usualmente no era repetitiva, una de las cuales habría sido la conjunción vaca/udjat que, por motivos que no podemos desarrollar en el presente trabajo, tuvo fortuna en el ámbito fenicio-púnico ${ }^{36}$.

A partir de estas premisas, podemos constatar la presencia de algunos ejemplares exportados al Levante Mediterráneo, donde se han detectado las fechas más altas para los ejemplares que responden al primer grupo considerado, con una datación de los siglos VIII-VII a. C., caracterizado por los tallos de papiro que se alzan sobre el lomo de la vaca y, en algunas piezas, por una elaboración compleja del ojo udjat.

Desde aquí, con toda la problemática que entraña la circulación de amuletos en la cuenca del Mediterráneo, el modelo llegaría a Cartago e incluso a la Península Ibérica, donde hemos documentado esta variante cuya cronología podría encuadrarse en la segunda mitad del siglo VII y primera del VI a. C.

Una vez introducido el modelo en talleres de Levante o quizá de Cartago, hecho difícil de dilucidar con la documentación existente, estos amuletos-placa debido a su gran aceptación en el ámbito fenicio-púnico habrían sido reproducidos, labor que no entraña dificultad debido a que su talla en esteatita, una piedra fácil de trabajar, sólo requiere cierto grado de destreza artesanal, y cuyo vidriado supone una realización que tampoco conlleva excesivas complicaciones.

Partiendo de este modelo original se habrían ido incorporando algunos detalles que afectarían a ambas iconografías, así, en el segundo grupo, en la escena de la vaca surge una variante que consiste en la desaparición de los tres tallos de papiro, sustituidos por la corola de una única flor, usualmente colocada en sentido horizontal, mientras que el udjat pierde su carácter alado y la pata de halcón para ser representado de forma más básica. No podemos señalar con seguridad el origen de esta nueva variante, siempre elaborada en esteatita, de la que se conocen algunos ejemplares en el Mediterráneo oriental como Chipre, pero por el elevado número localizado podría haber sido producido en algún enclave fenicio-púnico del Mediterráneo centro-occidental, tal vez Cartago, expandiéndose sus ejemplares a Sicilia, Cerdeña e Ibiza. Su cronología en Cartago se fija a finales del siglo VI y V a. C., mientras que en Chipre su contexto de aparición tiene un abanico cronológico entre el 600-450 a. C.

Coincidente parcialmente en el tiempo se detecta en el Mediterráneo centro-occidental otra variante, correspondiente a nuestro tercer grupo, cuya característica fundamental es la presencia de un ternero al que la vaca amamanta, una iconografía que podemos fácilmente reencontrar en el ámbito cultural fenicio-púnico, con manifestaciones afines sobre diferentes soportes.

Los ejemplares de este modelo localizados en la necrópolis de Cartago, proporcionan la cronología más alta documentada hasta la fecha, mediados del siglo VI a. C., sugiriendo una procedencia en esta zona aunque se han localizado estos amuletos en otros yacimientos fenicio-púnicos de Sicilia, Cerdeña, Ibiza y la Península Ibérica, lugar donde su presencia se data en la primera mitad del siglo V a. C. Tanto sus inicios como su final parecen ser más dilatados que la variante anteriormente señalada aunque ambas habrían sido en parte contemporáneas, algo que parece evidente por la similitud de las características que comparten estos amuletos-placa.

La última variante, que constituye nuestro cuarto grupo, se corresponde con una imitación muy degradada, llevada a cabo en amuletos elaborados siempre en fayenza de poca calidad, donde la representación de los dos tipos iconográficos sufren una gran esquematización. Su cronología es tardía, probablemente con comienzos en el siglo IV a. C. pudiendo prolongarse en el III a.

36 Esta es también la teoría de T Redissi (1991: 99-100). 
C., como muestran los hallazgos del norte de África. Su expansión es similar a la de las variantes anteriores: Sicilia, Cerdeña e Ibiza, con la excepción de la Península Ibérica, donde no hemos documentado este tipo de ejemplares.

Por último, algunos, muy pocos, amuletosplaca en fayenza recubierta de un vidriado verdoso muy característico, muestran una representación todavía más esquemática, incorporando la presencia de signos astrales. Su cronología no puede ser sugerida por la descontextualización de estos ejemplares, pero los datos estilísticos apuntan también a fechas tardías.

\section{BIBLIOGRAFÍA}

AA.VV. (1987): 30 ans au service du patrimonie. XXVIII ème centenaire de Carthage. Túnez.

ACQUARO, E. (1977): Amuleti egiziani ed egittizzanti del Museo Nazionali di Cagliari. (Collezione di Studi Fenici 10). CNR. Roma.

ACQUARO, E. (1982): La collezione punica del Museo Nazionale "Giovanni Antonio Sanna" di Sassari. Gli amuleti. R.S.F. 10 Suplemento.

ANDREWS, C. (1994): Amulets of Ancient Egypt. British Museum Press. Londres.

BARNETT, R. D. (1974): "The Nimrud Bowls in the British Museum”. RSF 2, 1133.

CARRIER, C. (2004): Textes des sarcophages du Moyen Empire égyptien. 3 Vol. I. Rocher. Mónaco.

CINTAS, P. y GOBERT, E. G. (1939): "Les tombes puniques du Jbel Mlezza". Rtun. 38-40, 135-198.

CLERC, G. (1991): “Aegyptiaca”, en V. Karageorghis et alii, La Nécropole d'Amathonte. (Tombes 110385), 1-157. Nicosia.

CLERC, G. et alii (1976): Fouilles de Kition II. Objets égyptiens et égyptisants: scarabeés, amulettes et figurines en pâte de verre et en faïence, vase plastique en faïence, Sites I et II, 1959-1975. Nicosia.

COWIE, P. J. (2004): "Amulets", en E. Mazar, The Phoenician family Tomb $n^{\circ} 1$ at the Northern cemetery of Achziv $\left(10^{\text {th }}-6^{\text {th }}\right.$ centuries BCE). CAM 10, 227-254. Barcelona.

DAYAGI-MENDELS, M. (2002) : The Akhziv Cemeteries. The Ben-Dor Excavations, 19411944. (Israel Antiquities Authority Reports 15). Jerusalén.

DI STEFANO, C.A. (2009): La necropoli púnica di Palermo. Dieci anni di scavi nell'area della Caserma Turköry. Fabrizio Serra editore. Pisa-Roma.
ERMAN, A. y GRAPOW, H. (eds.) (1982): Wörterbuch des aegyptischen Sprache. Vol. I. Leipzig, Berlín.

ESCOLANO, M. (2010): "Plaquita con ojo de Ra y vaca Mehet-Werek", en M. H. Olcina y J. J. Ramón (eds.). Objetos egipcios en Alicante (Catálogo de Exposición). Museo Arqueológico de Alicante. Alicante, 70-71.

FAULKNER, R. O. (1985): The Ancient Egyptian Book of the Dead. British Museum Press. Londres.

FERNÁNDEZ, J. H. y PADRÓ, J. (1986): Amuletos de tipo egipcio del Museo Arqueológico de Ibiza. (Treballs del Museu Arqueològic d'Eivissa i Formentera 16). Eivissa.

FRESINA, A. (1980): “Amuleti del Museo J. Whitaker di Mozia". SicArch 43, 27-50.

GABRICI, E. (1941) : "Rinvenimenti nelle zone archeologiche di Panormo e Lilibeo". NotScav XIX, 261-271.

GAMER-WALLERT, I. (1978): Äegyptische und ägyptisierende Funde von der Iberischen Halbinsel. (Tübinger Atlas des Vorderen Oriens, Reihe B 21). Reichert. Wiesbaden.

GARCÍA GANDÍA, J. R. (2009): La necrópolis orientalizante de Les Casetes (La Vila Joiosa, Alicante). Universidad de Alicante, Servicio de Publicaciones. Alicante.

GAUCKLER, P. (1915): Nécropoles puniques de Carthage. Vol. I. A. Picard. París.

GJERSTAD, E. et alii (1935): The Swedish Cyprus Expedition. Finds and results of the excavations in Cyprus. 1927-1931. Vol. I Texto, Vol II Láms. Estocolmo.

GUBEL, E. (coord.) (1986): Les Phéniciens et le monde Méditerranéen. Catalogue de l'exposition. Bruselas.

HERRMANN, C. (1994): Ägyptische Amulette aus Palestina/Israel. (Orbis Biblicus et Orientalis 138). Universitätsverlag Freiburg Schweiz. Vandenhoeck \& Ruprecht. Göttingen.

HERRMANN, C. (2002): Ägyptische Amulette aus Pälastina / Israel Band II. (Orbis Biblicus et Orientalis 184). Universitätsverlag Freiburg Schweiz. Vandenhoeck \& Ruprecht. Göttingen.

HERRMANN, C. (2006): Ägyptische Amulette aus Pälastina / Israel Band III. (Orbis Biblicus et Orientalis SA 24). Universitätsverlag Freiburg Schweiz. Vandenhoeck \& Ruprecht. Göttingen. 
HÖLBL, G. (1986): Ägyptisches Kulturgut im Phönikischen und Punischen Sardinien. 2 Vols. Études préliminaires aux religions orientales dans l’Empire Romain. Ed. J. Brill. Leiden.

HÖLBL, G. (1989): Ägyptischen Kulturgut auf den Inseln Malta und Gozo in phônikischen und punischen Zéit. Österreichische Akademie der Wissenschaften. Viena.

HORNUNG, E. y STAEHELIN, E. (1976): Scarabäen und andere Siegelamulette aus Basler Sammlungen (Ägyptische Denkmäler in der Schweiz I). Mainz.

KÁKOSY, L. (1982): "Mehet-weret", Lexikon der Ägyptologie IV, Cols. 3-4.

LILYQUIST, C. (2003): The Tomb of three Foreign Wives of Thuthmosis III. New Haven/Londres.

LÓPEZ GRANDE et alii (e.p.): Amuletos de iconografía egipcia procedentes de Ibiza. (Treballs del Museu Arqueològic d'Eivissa i Formentera 66). Eivissa.

MARKOE, G. (1985): Phoenician Bronze and Silver Bowls from Cyprus and the Mediterranean. Berkeley - Los Angeles.

MATTHIAE, P. (1962): "Il motivo della vacca che allatta nell'iconografia del Vicino Oriente Antico". Rivista di Studi Orientali 37, 1-31.

MAZAR, E. (2004): The Phoenician family Tomb $n^{o} 1$ at the Northern cemetery of Achziv $\left(10^{\text {th }}-6^{\text {th }}\right.$ centuries BCE). (Cuadernos de Arqueología Mediterránea 10). Universidad Pompeu y Fabra. Barcelona.

MENDLESON, C. (1987): "Amulets" (R. D. Barnett y C. Mendleson eds.) en Tharros, a catalogue of material in the British Museum from Phoenician and other tombs of Tharros, Sardinia. British Museum. Londres.

MOLINA, F. et alii (1982): Almuñécar en la antigüe dad: la necrópolis feniciopúnica de Puente de Noy. Granada.

MOSCATI, S. (1988 dir.): I Fenici. Gruppo Editoriale Fabbri. Milán.

MYRES, J. L. y OHNEFALSCH-RICHTER, M. (1899): A Catalogue of the Cyprus Museum. Oxford.

OHNEFALSCH-RICHTER, M. (1893): Kypros. Die Bibel und Homer. Asher. Berlín.

PADRÓ, J. (1983): Egyptian-Type Documents from the Mediterranean Littoral of the Iberian Peninsula before the Roman Conquest. Vol II. Study of the Material. from Western Languedoc to Murcia. E. J. Brill. Leiden.
PADRÓ, J. (1985): Egyptian-Type Documents from the Mediterranean Littoral of the Iberian Peninsula before the Roman Conquest. Vol III. Study of the Material. Andalusia. E. J. Brill. Leiden.

PATRONI, G. (1904): "Nora colonia fenicia in Sardegna". MAL 14, col. 109-267.

PÉREZ DIE, M. C. (2010): "Los amuletos. Catálogo", en C. Pérez Die (ed.), Heracleópolis Magna (Ehnasya el Medina, Egipto) La necrópolis "real" del Tercer Período Intermedio y su reutilización. Fundación Barrero. Madrid, Vol. II, 524564.

PESCE, G. (1961): Sardegna punica. Fratelli Fossataro. Cagliari.

PETRIE, W. M. F. (1886): Naukratis I, 1984-1985. (Egypt Exploration Found 3). Londres.

PETRIE, W. M. F. (1888): Tanis II, Nebesheh and Deffenneh. Londres.

PETRIE, W. M. F. (1891): Illahun, Kahun and Gurob. David Nutt. Londres.

PETRIE, W. M. F. (1914, 1972 reimp.): Amulets Illustrated in the Egyptian Collection in University College London. Londres.

PINCH, G. (1993): Votive Offerings to Hathor. Griffith Institute, Ashmolean Museum. Oxford.

PLAS, D. van der y PÉREZ DIE, M. C. (eds.) (2006) : Tesoros Egipcios en Europa: Vol. 7 Museo Arqueológico Nacional, Madrid. Centre for Computer-aided Egyptological Research. Horssen. Holanda.

PLUTARCO: De Iside et Osiride. (Traducción y comentarios de J. Gwyn Griffiths), University of Wales Press, Swansea, 1970.

PUGLISI, S. (1942): “Cagliari. Scavi nella necropoli punica a inumazione di S. Avendrace". NotScavi serie 7,3, 92-106.

REDISSI, T. (1987) : Étude des Amulettes de type égyptien et égyptisant et divers Aegyptiaca de Carthage (VII-II av. J. C.) et de la Méditerranée

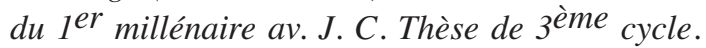
Paris IV, Sorbonne, (dactylographiée).

REDISSI, T. (1991): "Étude de quelques amulettes puniques de type egyptisant". Revue des Études Phéniciennes-Puniques et des Antiquités Libyques 6, 95-139.

REISNER, G. A. (1907): Amulets, Catalogue General des Antiquités Égyptiennes du Musée du Caire $n$. 5.218-6.000 et 12.001-12.527. El Cairo. 
RIDDER, A. de (1911): Collection de Clercq, VII, 1: Les bijoux et les pierres gravées. París.

SAVIO, G. et alii (2004): “Amuleti punici di Tharros : Tipi e metodiche analitiche" en E. Acquaro y G. Savio (dirs.), Studi iconografici nel Mediterraneo Antico. Iconologia e aspetti matrici, pp. 125-153. Sarzana.

SFAMENI GASPARRO, G. (1973): I culti orientali in Sicilia. (Études préliminaires aux religions orientales dans l'Empire Romain 31). E. J. Brill. Leiden.

SMITH, A. (1900): “Amathus" en Murray et alii, Excavation in Cyprus, 118.

TARAMELLI, A. (1912): "La necropoli punica di Predio Ibba a S. Avendrace, Cagliari (Scavi del 1908)". MAL 21, Cols. 45-224.

TERMINI, A. (1995): “Amuleti dalla necropoli di Solunto”, SicArch 87-89, pp 97-106.

UBERTI, M. L. (1988): “Gli avori e gli ossi” en S. Moscati (dir.). I Fenici. Gruppo Editoriale Fabbri. Milán, 402-421

VELÁZQUEZ, F. (2007): El Dios Bes: De Egipto a Ibiza. (Treballs del Museu Arqueològic d'Eivissa i Formentera 60). Eivissa.
VERCOUTTER, J. (1945): Les objets égyptiens et égyptisants du Mobilier Funéraire Carthaginois. (Bibliothèque Archéologique et Historique XL). París.

VERGA, S. (1981): "Considerazioni in margine al significato magico-religioso e alla tipologia dei "ugiat" conservati nel Museo J. Whitaker di Mozia". SicArch 43, 15-24.

VIVES, A. (1917): Estudio de Arqueología cartaginesa. La necrópoli de Ibiza. Junta para la ampliación de Estudios e Investigaciones Científicas. Madrid.

WARD, W. A. (1991): "The scarabs, scaraboid and amulets-plaque from Tyrian cinerary urns". Berytus 39, 88-101.

WINLOCK, H. E. (1948): The Treasure of Three Egyptian Princesses. The Metropolitan Museum of Art. Nueva York.

YOYOTTE, J. (1987): Tanis. L'or des pharaons. Catálogo de la Exposición (26 marzo - 20 julio, 1987). París. 
